\title{
The use of video feedback in teaching process- approach EFL writing
}

\section{Sertaç Özkul ${ }^{1}$ | Deniz Ortaçtepe ${ }^{2}$}

${ }^{1}$ Trakya University

${ }^{2}$ Bilkent University

\begin{abstract}
This experimental study investigated the use of video feedback as an alternative to feedback with correction codes at an institution where the latter was commonly used for teaching process-approach English as a foreign language (EFL) writing. Over a 5-week period, the control and the experimental groups were provided with feedback based on comments and correction codes and video feedback, respectively, and the extent of feedback incorporation was analyzed through descriptive and inferential statistics. In addition, a questionnaire was administered to the experimental group to explore their perceptions of video feedback. The findings show that teacher feedback delivered in the form of videos is more effective than written feedback when EFL learners revise their written work in process writing. The study confirms that video feedback is more information-rich, and in return results in more correction in learners' subsequent drafts. The findings imply that video feedback, because of its features of conferencing and multimodality, is an effective method of providing EFL learners with teacher feedback and is therefore eligible for classroom practice and for future research.
\end{abstract}

\section{1 | INTRODUCTION}

Teachers' corrective feedback involves the process of responding to language learners' written work by explaining errors and offering formative ideas and constructive comments that they can use to revise their papers for the following drafts (Ferris, 1997, 1999; Hyland \& Hyland, 2006; Johnson, 2008; Truscott, 2007). Computer technologies in that sense can offer ways for language 
teachers to improve the effectiveness of corrective feedback in writing instruction. For instance, video-capture tools (i.e., screencasts) can provide opportunities for language learners to improve their writing skill through recorded videos in which their instructors comment on and offer corrections to their written assignments. This study, thus, aims to explore how English as a foreign language (EFL) learners respond to video feedback, and in return, what influence video feedback has on their writing.

\section{2 | LITERATURE REVIEW}

Technology-enhanced feedback in the form of audios or videos successfully combines written feedback and conferencing (Hyland, 2003; Keh, 1990); can be listened to, watched, and replayed beyond the boundaries of time and place; and serves learners as a portfolio to track their own performance. In Lunt and Curran's (2009) study investigating the effectiveness of audio versus written feedback, 60 students were provided feedback through MP3 files which were recorded by Audacity [open-source computer software]. Their findings showed that the learners felt more cared for by their teacher when they were provided with audio feedback. In Butler's (2011) study again using Audacity, the personal nature of feedback was the prominent feature of audio feedback as reported by law students. While these two studies provide evidence that audio feedback can improve student writing, the use of screencast, which is the broadcast of videorecordings of one's on-screen activities and corresponding comments, has gained popularity in the field of educational research as a way of providing video feedback on students' writing (Mann, 2015; Seror, 2012; Silva, 2012; Stannard, 2006).

According to Bitchener, Young, and Cameron (2005), corrective feedback is most effective when it is individualized in the form of one-on-one conferences with students, which is oftentimes difficult to schedule especially with larger classes (Butler, 2011; Keh, 1990). Although it may save time for the teachers, the use of correction symbols may also become problematic as they are prone to misinterpretations especially with lower proficiency levels (Lee, 2003; Seror, 2012). Video feedback, in that sense, can help teachers overcome some of these challenges in providing feedback. More specifically, learners can submit their work in any form of electronic document, and teachers can record videos by using all the tools of their word processors while they speak to their microphones and their webcam records their video image into the screen-capture video. In other words, teachers can reflect on learners' errors by using all forms of written feedback (e.g., comments, rubrics, correction codes), enrich their feedback by the audiovisual aids of multimedia, and humanize the feedback procedure as in conferencing (Stannard, 2006, 2008).

As a matter of fact, video feedback has found its place in higher education (Crook et al., 2012; Seror, 2012; Thompson \& Lee, 2012). Crook et al. (2012) report on the findings of a recently piloted study that aimed to evaluate professors' and students' perceptions toward video feedback. According to their findings, most students enjoyed being addressed with videos and found video feedback more encouraging than written feedback. Also, they were actively engaged with the feedback in videos and a majority of them revisited their video feedback while revising their papers (Crook et al., 2012). In another study, Thompson and Lee (2012) used screencasting as a form of video feedback in a college-level writing course. The students' responses to the web-based survey revealed that they had difficulty interpreting written feedback, usually provided in the margins of the paper, and therefore found video feedback more meaningful due to its audiovisual features that make it more conversational. In Seror's (2012) study, the author not only explains his own journey as a second language writing teacher using video feedback, discussing the advantages and disadvantages, but also presents his students' perceptions regarding video feedback. Although there is 
growing interest in the idea that screen-capture videos can be helpful in understanding students' engagement with writing outside the classroom context (Seror, 2013) and in providing written feedback (Crook et al., 2012; Seror, 2012; Stannard, 2006, 2008; Thompson \& Lee, 2012), prior studies have focused only on students' perceptions regarding video feedback. The pedagogical and practical effectiveness of video feedback in second and foreign language writing contexts - in other words, the extent to which language learners improve their writing based on video feedback-remains underexplored.

\section{3 | THIS STUDY}

Following Mann's (2015) call for empirical studies to explore students' perception and uptake of feedback in written versus audio/video forms, the present study aims to explore how EFL learners respond to video feedback, and in return what influence video feedback has on their writing. The study addresses the following research questions:

1. To what extent do learners in written and video-feedback groups incorporate feedback into their subsequent drafts?

2. In what ways does the form of feedback (video or written) affect how correctly learners incorporate explicit, simple mechanical, complex mechanical, and organizational feedback in their subsequent drafts?

3. What are learners' perceptions of video feedback in EFL writing?

\section{4 | METHOD}

\section{1 | Data Collection}

This study was conducted at an English preparatory school of a private university in Istanbul, Turkey. At the time of the study, the English language learners at this institution seldom had the opportunity to have individual conferences with their instructors due to classroom sizes that ranged between 24 and 28 members. Hence, students relied on teacher feedback that came with comments and correction codes on their papers because timetables rarely allowed teachers to work with students individually. The researchers collected data in two B1 level classes (i.e., intermediate, according to the Common European Framework of Reference). These two classes, consisting of 47 EFL learners, were taught by two different instructors following the same syllabi and textbook, and hence similar activities were used in both classes. The reason for working with two different instructors is that they were the only volunteers who taught at the same proficiency level. The first author of this study was also an instructor working in the same institution, and was familiar with the curriculum; instruction; and, more specifically, the feedback provision process in this institution. Therefore, in order to control the differences in the quality and quantity of feedback coming from two different instructors, the first author became the main correspondent for providing video feedback. This decision was made also because the course instructors were reluctant to be trained in how to provide video feedback to their students due to their busy schedules. Thus, the instructors continued their pacing in the curriculum with no attention to or emphasis on the feedback provided by the researchers. The researchers randomly assigned one of these classes as the control group (24 students, 14 male and 10 female), and the other as the experimental group (23 students, 9 male and 14 female). The students were all young adults between the ages of 17 and 23 . 
The usual procedure in these writing classes was that throughout an 8-week module, the instructor delivered the lesson in 4 contact hours per week. After the last writing class of the week, students were assigned a five-paragraph essay in which they needed to follow academic writing standards (e.g., appropriate paragraphing, formal language, developing scholarly discussions). In order to keep the portfolio process standardized, the essay topic was limited to one (i.e., all the students of the same level wrote about the same topic). The writing topics of the essays examined in this study are as follows:

Week 1: Write a biography of an important person.

Week 2: Compare and contrast alternative medicine and modern medicine.

Week 3: Write about positive and negative aspects of your life.

Week 4: Write a summary about the text (reading text about animal intelligence) and reflect on your ideas.

Week 5: Explain why people should donate their organs to medical research.

The study took place in three steps: (1) feedback provision over a 5-week period, (2) analysis of the data coming from the learners' drafts, and (3) administration of the questionnaire at the end of the study.

\section{2 | Feedback Provision}

After the orientation meetings with the students and the writing teachers of the two classes, the first author of this study started providing feedback on the first drafts of the learners' assignments for both groups. All drafts were written by hand by the students in both groups because of the institutional policy. The researchers provided the control group with written feedback by following the standard policy in feedback provision at the school: making some overall comments (both positive and negative) and marking the mistakes and errors in learners' papers using the correction codes. The experimental group was provided with the same kind of feedback (e.g., correction symbols and overall comments), but in the form of videos with the help of computer technology.

Since the institution did not allow students to submit their assignments online through e-mail or post them on an online course management system, the hard copies of the students from the experimental group were first scanned to create PDF files so that the drafts were available as soft-copies. With the help of PDF-Xchange Viewer (https://www.tracker-software.com/product/pdf-xchange-vie wer, open source computer software for editing PDFs), those files were then marked and commented on with correction codes. This on-screen marking and commenting process was also screen-captured and saved by the researchers with the help of Screencast-O-Matic (https://screencast-o-matic.com/, open-source computer software), which is widely used by software developers, gamers, librarians, educators, and researchers to produce and disseminate videos of themselves carrying out tasks on computers (Seror, 2012, 2013). This software was chosen among others because it was suggested by Mann (2015) and Seror (2013) as a better starting point due to its observed reliability and the simplicity of its interface, as well as for its feature of enabling the researcher/teacher's webcam to appear on the screen. The videos in this study included the researchers' feedback addressing both structural and organizational problems as if he were speaking to the students, with his real-time video image at the left upper corner of the screen, voice recording, cursor movements on students' assignments, and sometimes reference sources (e.g., digital English dictionary or collocations dictionary) (see Figure 1 for a sample screenshot of a video feedback session along with its transcript). The final step was publishing the video files individually on YouTube (the videos were too large to be sent as e-mail 
Researcher: Hello (student's name). This is (researcher's name)... and here is your feedback for your essay. (Scrolling down the essay) Very clear start but here we have some problems. The first one is we don't use for with the verb agree. Instead, there is another preposition. Please use your dictionary and look it up.

Secondly, modern treatment...modern treatment... Singular or plural? ... because you follow it with are. Therefore, it needs to be plural as you can see so this (treatment) needs to be plural...

OK, this adjective makes sense but you can always find something better (opens the Oxford University press dictionary), for example..treatment... medical treatment. You want to use a positive adjective but there are also other adjectives that can be used together with treatment, so why don't you use one of them (showing the list of adjectives on the screen) instead of yours?

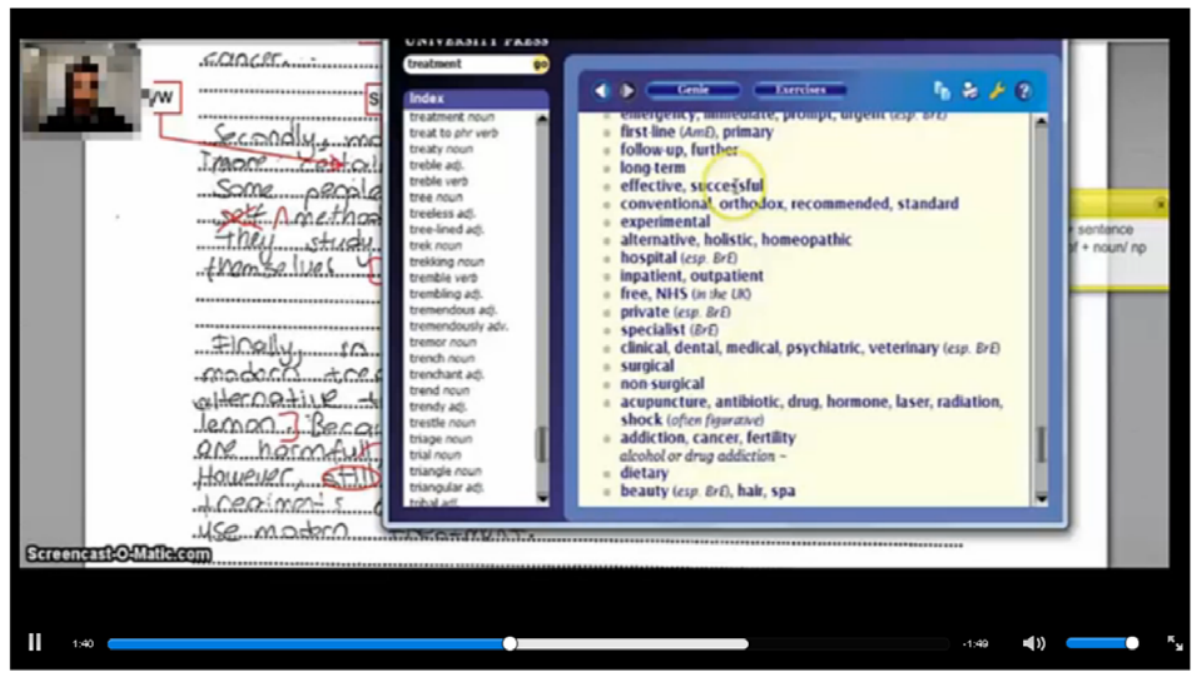

F IGURE 1 Sample screenshot of a VIP along with its transcript

attachments to students' inboxes). The feedback provided to both groups by the first author was also checked by the second author before it was sent out to the students to make sure that the correction codes were used uniformly across participants. Once the participants were provided with feedback on their first drafts, they were requested to submit their second drafts within a week, and these drafts also received feedback from the researchers. Because the main concern of the study was to examine how much teacher feedback was correctly incorporated into learners' second drafts, the researcher focused on both mistakes and errors without operationalizing the difference between them in order to understand the underlying reasons behind learner language deficiencies. Task-related (e.g., the type of genre), meta-cognitive, and psychological factors were not accounted for, because these were beyond the scope of this research and students in both control and experimental groups would be equally influenced by these. Also, by examining feedback incorporation, the researchers could examine the revisions that the students made on their own either by watching the video feedback or by looking at written feedback. Both feedback types in that sense reinforced students' agency in terms of assessing teacher feedback and making their own decisions in terms of how to revise their papers.

\section{3 | Data Analysis}

The researchers used a cover sheet for each learner to record the amount of feedback provided in the first draft and how much of it was incorporated into the second draft. Thus, feedback 
TAB LE 1 Number of students who submitted both their first and second drafts throughout the study

\begin{tabular}{lll} 
& $\begin{array}{l}\text { Experimental group } \\
\text { (Class size: 23 learners) }\end{array}$ & $\begin{array}{l}\text { Control group } \\
\text { (Class size: 24 learners) }\end{array}$ \\
\hline Week 1 & 15 & 14 \\
\hline Week 2 & 14 & 15 \\
\hline Week 3 & 13 & 10 \\
Week 4 & 11 & 14 \\
\hline Week 5 & 12 & 16 \\
\hline
\end{tabular}

incorporation in this study refers to the accurate use of teacher feedback on subsequent drafts. For example, if a student accurately followed a suggestion or made an accurate revision based on the feedback provided by the teacher in his/her subsequent drafts, that was considered a successful incorporation of teacher feedback and formed the basis of the data analysis.

The cover sheet was divided into four main categories of feedback so as to track how learners used different feedback forms (see the Appendix for the cover sheet). The first category, explicit feedback, involved explicit corrections of learners' mistakes and errors. Feedback for capitalization, pluralization, word order, and unnecessary words were also accepted as explicit feedback because these types do not require any complex language ability to incorporate. The second category addressed some simple mechanical mistakes and errors, and the third category involved complex mechanical mistakes and errors. Mechanical mistakes and errors were recorded in two separate categories because some of them required metalinguistic awareness and grammatical processing (e.g., missing word, subject-verb agreement, fragment, reference) whereas others did not (e.g., spelling, punctuation, and articles). The final category recorded feedback on organizational issues such as length of text, missing or extra paragraphs, supporting ideas and examples, thesis statement, introduction, repetition, and so on. Table 1 shows the number of papers retrieved in two drafts at the end of the study.

The cover sheets only recorded feedback provided in the first draft and feedback incorporated into the second draft - that is, mistakes and errors newly occurring in the second draft were not taken into consideration. For the descriptive analysis, the researchers compared the feedback provided on the first drafts with the students' second drafts to find out about their level of feedback incorporation according to the different feedback categories mentioned above and in total for each assignment. These descriptive findings were then analyzed with the help of inferential statistics to compare the experimental and control groups. Due to the small sample size, the researchers ran a Mann-Whitney $\mathrm{U}$ test (the nonparametric equivalent of an independent samples $t$-test) in order to answer Research Questions 1 and 2.

\subsection{The Perception Questionnaire}

A perception questionnaire was only administered to the experimental group $(n=23)$ because it involved items comparing the two forms of feedback. The questionnaire included 17 items in three separate parts. The first part, with seven items, explored students' general perceptions regarding written teacher feedback in writing classes. The items addressed in this part focused on the role of teacher feedback and the use of correction codes in improving writing skills and in enabling students to prioritize their learning needs. The second part, with nine items, aimed to understand how video feedback was perceived by the learners-more specifically, level of computer literacy and the use of the videos (how many times did they watch each video? how much time did they spend 
on them?), the practicality of the videos, and the comparison of video and written feedback. The last part involved only one gap-filling item to explore the participants' ideas for the strengths and weakness of video feedback as well as ways to improve the process. Data resulting from the first two parts of the questionnaire were analyzed in terms of descriptive statistics and the third part was analyzed qualitatively through thematic analysis (Boyatzis, 1998).

\section{5 | RESULTS}

\section{1 | Overall Comparison of Video and Written Feedback}

In order to answer the first research question, the researchers conducted a Mann-Whitney $U$ test to compare the groups of video and written feedback in terms of feedback incorporation. As shown in Table 2, according to the descriptive statistics obtained the learners in the experimental group incorporated more feedback into their second drafts than the learners in the control group across all assignments. Table 3 presents whether these differences between the groups were statistically significant across all assignments. Table 3 shows that the difference between the video and written feedback groups was statistically significant in Assignment $2(U=62.5, p=.030)$, Assignment 3 $(U=24.0, p=.004)$, and Assignment $4(U=33.0, p=.007)$ - that is, the video feedback provided for the experimental group for their first drafts in Assignments 2, 3, and 4 helped these learners incorporate more feedback into their second drafts. However, for Assignments 1 and 5, where there was no statistically significant difference between the groups of video and written feedback, the form of feedback made no difference when the learners were asked to write their second drafts. This finding may be explained in various ways. As far as the last assignment is concerned, because the learners in the experimental group received video feedback for the first time

TA B LE 2 Descriptive results for feedback incorporation across all assignments

\begin{tabular}{|llll|}
\hline Feedback incorporation & Group & Mean rank & Sum of ranks \\
\hline Assignment 1 & Experimental & 15.97 & 239.5 \\
& Control & 13.96 & 195.5 \\
\hline Assignment 2 & Experimental & 18.04 & 252.5 \\
& Control & 12.17 & 182.5 \\
\hline Assignment 3 & Experimental & 15.15 & 197 \\
& Control & 7.9 & 79 \\
\hline Assignment 4 & Experimental & 17 & 187 \\
& Control & 9.86 & 138 \\
\hline Assignment 5 & Experimental & 17.46 & 209.5 \\
& Control & 13.26 & 225.5 \\
\hline
\end{tabular}

TAB LE 3 Overall comparison of video and written feedback across all assignments

\begin{tabular}{llllll}
\multicolumn{5}{c}{ Feedback incorporation } \\
\cline { 2 - 6 } & Assignment1 & Assignment2 & Assignment3 & Assignment4 & Assignment5 \\
\hline Mann-Whitney U & 90.5 & 62.5 & 24 & 33 & 72.5 \\
Exact sig. (1-tailed) & .270 & $.030^{*}$ & $.004^{*}$ & $.007^{*}$ & .099 \\
\hline
\end{tabular}

$* p<.05$. 
and they were not accustomed to this new form of feedback, they might have found the process challenging. For instance, one learner, in his response for the gap-filling item on the questionnaire, indicated that he could not benefit from video feedback greatly because the duration of the study was not enough to get accustomed to video feedback. Therefore, the amount of correction learners incorporated into their second drafts in Assignment 1 might have remained relatively restricted. As for the last assignment, the number of control group students who completed both the first and second drafts outnumbered the number of experimental group students who completed both, 16 and 12, respectively (see Table 1). This discrepancy in the fifth assignment might suggest that learners in the experimental group were tired of writing assignments and the amount of feedback provided in the videos. The amount of work required both by the teacher who provides video feedback and the student who is faced with more enhanced feedback than he or she is used to with correction codes definitely raises issues about the practicality of video feedback. Another issue worth mentioning regarding Assignment 5 is the topic: "Explain why people should donate organs to medical research." Although there were no comments in the qualitative findings on the assigned topics, some students might have found the last topic biased or did not have much to say on this issue. To overcome this limitation, both "agree" and "disagree" papers were accepted as relevant responses by the researchers as long as the students supported their arguments. However, the topic itself might have led to a lower response rate for this last assignment.

\subsection{Comparison of Different Feedback Categories}

As a second step, the amount of correction incorporated by the learners for different feedback categories - namely, explicit, simple and complex mechanical, and organizational-was examined to explore how feedback from different categories was incorporated by the learners into their subsequent drafts. A Mann-Whitney U test was conducted to examine any statistical differences between the two forms of feedback. As shown in Table 4, the experimental group utilized more teacher feedback than the control group. The figures are close for explicit feedback, but the difference increases in the simple mechanical feedback category and almost doubles in the complex mechanical and organizational feedback categories (see Table 5).

\subsection{1 | Explicit feedback}

As Table 5 shows, the results indicate a statistically significant difference for all the feedback types except explicit feedback. Most of the latter type of feedback provided for the learners' first

TA B LE 4 Descriptive results for feedback incorporation across different types of feedback

\begin{tabular}{|llll|}
\hline & Group & Mean rank & Sum of ranks \\
\hline Explicit feedback & Experimental & 17.33 & 260 \\
& Control & 15.76 & 268 \\
\hline Simple mechanical & Experimental & 19.70 & 295.5 \\
\hline Complex mechanical & Control & 13.68 & 232.5 \\
\hline Organizational feedback & Experimental & 21.30 & 319.5 \\
& Control & 12.26 & 208.5 \\
\hline
\end{tabular}


T A B L E 5 Comparison of video and written feedback across different feedback types

\begin{tabular}{llllc} 
& \multicolumn{2}{l}{ Feedback incorporation } & & \\
\cline { 2 - 5 } & $\begin{array}{l}\text { Explicit } \\
\text { feedback }\end{array}$ & $\begin{array}{l}\text { Simple } \\
\text { mechanical }\end{array}$ & $\begin{array}{l}\text { Complex } \\
\text { mechanical }\end{array}$ & $\begin{array}{l}\text { Organizational } \\
\text { feedback }\end{array}$ \\
\hline Mann-Whitney U & 115 & 79.5 & 55.5 & 57.5 \\
Exact sig. (1-tailed) & .321 & $.035^{*}$ & $.003^{*}$ & $.003^{*}$ \\
\hline
\end{tabular}

$* p<.05$.

drafts was incorporated correctly into the second drafts no matter how it was conveyed (video vs. written). This finding may imply that learners accepted any explicit correction provided by the teacher without hesitation. Existing literature which finds that learners value teacher feedback more than any other channel supports our finding on the role of explicit teacher feedback (e.g., Ferris, 1997, 1999; Hyland, 2003; Montgomery \& Baker, 2007). More importantly, direct correction and simple underlining of errors have been found to be preferred by learners because that kind of feedback is found to be more beneficial, timesaving, and comprehensible (Chandler, 2003).

\subsection{2 | Simple mechanical feedback}

Feedback items in this category included spelling, punctuation, and articles, requiring learners to choose the correct form among alternatives. The results indicated a statistically significant difference in this type of feedback $(U=79.5, p=.035)$ - the amount of incorporation for simple mechanical feedback was highest in the experimental group. For this category, video feedback might have yielded some advantages for the learners because the researchers provided hints in the videorecordings (e.g., indicating the initials of words when there was an article error, intonation, mimics, the way a sentence is read when there is a missing comma).

\subsubsection{Complex mechanical feedback}

Another statistically significant difference was observed in complex mechanical mistakes and errors (e.g., verb tense, subject-verb agreement, missing words, prepositions, word collocations) $(U=$ $55.5, p=.003)$. Learners in the video feedback group incorporated more corrections into their subsequent drafts in this category than the learners in the control group who received written feedback. This finding again confirms the advantages of video feedback for student writers while they revise their work. Lee (2003) argues that teacher feedback is sometimes misinterpreted by learners in traditional practice especially when the the suggestion is indicated with a correction symbol in the margin of a paper without further comment. Video feedback is more reliable because it is more information-rich (Stannard, 2006, 2008). Although mistakes and errors are marked with the same kind of correction symbols as in the written feedback, in video the teacher can comment on the source of the problem and possible solutions. In this study, this procedure incorporated the advantages of graphic organizers and indicators. Presumably, learners detect the reasons for mistakes and errors more accurately and easily, and they do the necessary revisions accordingly.

\subsection{4 | Organizational feedback}

Feedback on organization also resulted in more correction in the experimental group's subsequent drafts with a statistically significant difference $(U=57.5, p=.003)$. One reason why video 
feedback was superior to written feedback in this study might be the fact that feedback related to organization of a written work requires more visualization and negotiation of learners' mistakes and errors - that is, delivering this kind of feedback can be complicated by the causes of mistakes, errors, or deficiencies related to organization, which cannot always be indicated with correction symbols or footnotes. The video feedback recorded in this study involved elements of conferencing, during which the students received comments with rich input. For example, if an issue was related to paragraphing and essay organization, the researchers were able to scroll up and down the page to give ideas for better organization, elicit new ideas, and show why some ideas or supporting examples were irrelevant. This finding then concurs with Seror (2012) and Thompson and Lee (2012) in terms of the benefits of video feedback to address higher order issues in writing. For instance, Thompson and Lee's (2012) study found that students responded to video feedback by attending to the "big picture" rather than focusing on surface-level issues. According to Seror (2012), being able to "jump on screen from a student's assignment to outside resources such as a Web page or course documents relevant to the feedback being offered" (p. 111) is one of the aspects of video feedback that contributes more to the organizational issues in writing.

\section{3 | Learners' Perceptions}

This section summarizes the findings of the questionnaire administered to the experimental group at the end of the study to investigate learners' overall perceptions toward video and traditional feedback. Each percentage referred to below entails a finding from a single questionnaire item.

\subsection{1 | Learners' perceptions regarding written feedback}

Results indicated that $46 \%$ of the learners did not think traditional teacher feedback helped them improve their writing skill in English (Item 1) while 68\% believed that the correction symbols did not help them at all (Item 4). Seventy-seven percent of the learners found teacher feedback valuable to prioritize their learning needs in order to improve their writing in English (Item 3), while $69 \%$ of them agreed that the more mistakes and errors were marked on their papers, the more they could develop their writing skills (Item 2). This finding confirms Hyland's (2003) views on teacher feedback: learners want their mistakes and errors to be corrected. When asked whether conferencing would be a better way to negotiate their mistakes and errors (Item 6), all learners agreed (100\%), a finding confirming the positive aspects of tutor conferencing (Goldstein \& Conrad, 1990). However, in our study $77 \%$ of the participants indicated not being able to meet their teachers for conferencing to receive feedback on their written work (Item 7).

The perception questionnaire also examined what form of feedback language learners preferred. Seventy-three percent mentioned that they preferred more explicit feedback (Item 5), confirming Chandler's (2003) study which found explicit feedback to be timesaving and meaningful. However, this finding should be interpreted with caution because of the possible adverse effects of explicit feedback; learners might lose their confidence in writing when solely given explicit feedback (F. Hyland, 1998).

\subsection{2 | Learners' perceptions regarding video feedback}

When the learners were asked to compare the two forms of feedback, most indicated positive attitudes toward video feedback, a finding in line with studies by Seror (2012) and Silva (2012). All the learners believed that video feedback offered more information than correction 
codes did (95\% for Item 9), and that teacher/researchers had spent more time providing feedback (100\% for Item 11). Video feedback was found to be more convenient: $60 \%$ agreed that they could watch video feedback wherever and whenever they wanted (Item 13), and 85\% said they watched the recorded videos more than once (Item 8). The participants also reported being more careful while redrafting their assignments because the teacher/researchers addressed them in person (91\% for Item 12).

Despite their positive attitudes toward video feedback, only 62\% stated that they enjoyed redrafting their work with the help of videos (Item 10), a finding that might be explained by possible negative attitudes toward the writing tasks/topics or the writing class in general. It is true that the learners who participated in this study were already equipped with fundamental computer skills (91\% for Item 16), but this finding does not mean they were all audiovisual learners. Some learners like to work with pen and paper whereas others prefer visual aids. Similarly, some learners might not have access to their computers and the Internet 24 hours a day. According to the World Bank (2015), although 54\% of people in Turkey use the Internet, only $12 \%$ have fixed broadband Internet subscriptions (for the United States, these numbers are $74.5 \%$ and $31 \%$, respectively). Thus, for some learners being able to watch their feedback any time they want is not a true advantage. Yet, when asked to compare traditional and video feedback, they all agreed that video feedback was better because it delivered more information, and thus they would favor video feedback for their future assignments (100\% for Items 14 and 15).

\subsection{3 | Open-ended responses regarding video feedback}

Confirming the above findings, the learners' responses to the questionnaire included positive comments related to video feedback. For example, five students explicitly stated that they were happy with the video feedback practice, and three of them mentioned that they would prefer to be provided with video feedback in future classes. However, some learners raised concerns related to video feedback; namely, late delivery and the duration of the videos.

According to nine participants, a weakness of video feedback was late delivery. Because the researcher who provided them with feedback was not the instructor of either of the two classes involved in the study, the delivery of the drafts to the researchers and back to the learners required careful logistics that led to delays. Loss of time (3-7 days between the submission of the assignments and video feedback) was inevitable, thus creating dissatisfaction for some of the students. In addition, three students reported that the videos recorded for them were too lengthy. The screencapture software enabled the researchers to record feedback videos up to $15 \mathrm{~min}$ long. The length of videos depended on the amount of feedback that was marked on the learners' first drafts; that is, the papers of those learners required longer videos because they were given more feedback.

\section{6 | DISCUSSION AND CONCLUSION}

This study found that teacher feedback delivered through videos appeared to be more effective than written teacher feedback in improving EFL learners' writing skills. Descriptive results confirmed that learners in the experimental group did better than the learners in the control group in all assignments in terms of incorporating the feedback provided into their subsequent drafts. This difference was statistically significant in three out of five assignments (Assignments 2, 3, and 4), and in three out of four feedback categories (simple and complex mechanical, and organizational feedback). 
The effectiveness of video feedback can be explained by its features of conferencing and multimodality. First, video feedback includes elements of conferencing (Mann, 2015; Seror, 2012; Thompson \& Lee, 2012). Although the interaction in the video feedback in this study was onesided, learners were addressed by the researchers in person as if it were a conferencing session. Both Seror (2012) and Mann (2015) agree that video adds greater personalization, emotional color, and relationship building to the feedback provided to learners, thus increasing their sense of authenticity when writing. The role of conferencing has been stressed in the literature because it creates opportunities for learners to negotiate their mistakes and errors in written work, thus enhancing the possible constructive effects of teacher feedback. Tutor conferencing has been found to encourage more correction in learner writing than peer feedback (Mukundan \& Nimehchisalem, 2011) because learners take tutor conferences more seriously and incorporate most of the modifications the tutor advises (Goldstein \& Conrad, 1990). A second asset of video feedback is its multimodality due to its audiovisual characteristics (Mann, 2015; Seror, 2012). In the present study, video feedback involved speech, videos, learners' written work, and referencing tools like digital dictionaries, pointers, markers, graphic organizers, as well as the researcher's webcam image on the screen while providing feedback. Beyond being text-based, it appeals to a wider range of learning styles (Seror, 2012) and multiple intelligences rather than only linguistic intelligence as in the case of written feedback (Stannard, 2008).

Apart from these two features, the novelty of the practice might also have resulted in the superiority of video feedback in this study. Lunt and Curran (2009), responding to the growing discontent of the students in their classes, investigated how learners would react to audio feedback. They found learners to be happier with the new kind of feedback because it was more meaningful and comprehensible. Similarly, in this study, video feedback might have appealed to the participants' needs; they also complained about similar issues regarding written feedback (as mentioned in the questionnaire findings). Although the B1 level (i.e., intermediate) students participating in this study did not complain about misinterpreting correction codes as a disadvantage of written feedback as Lee (2003) has suggested, they definitely did prefer the combination of correction codes and video feedback. The fact that language learners enjoyed the process of receiving audiovisual feedback while redrafting their written work might suggest that video feedback could be especially useful in low-level classes where students need more assistance and "extra visual scaffolding" (Seror, 2012, p. 110). Likewise, Crook et al. (2012) reported that $80 \%$ of their learners enjoyed being addressed in the videos and actively engaged with the video feedback they received. Again, in this study, the questionnaire results revealed that the students were content with video feedback, and they would like to be provided with video feedback for future assignments.

The findings also contribute to the literature on teacher feedback, because the number of students' mistakes and errors decreased in subsequent drafts regardless of the form of feedback they were given (e.g., video or written feedback). This finding is consistent with numerous studies in the literature indicating the role of teacher feedback in process writing in terms of enabling learners to refine and revise their written work (Ferris, 1997, 1999), to reduce the number of mistakes and errors in their writing (Chandler, 2003), and to perform better than the no-feedback group in general (Bitchener, 2008).

The main limitation of this study results from its being integrated into an ongoing teaching program. The researchers had to collect data from the assignments, topics, genres that were previously determined by the curriculum unit of the school and work with two different teachers in the two classes assigned as control and experimental groups. Although both classes were assumed to be at the same proficiency level and the teachers were using the same coursebook and activities in these classes, there were individual differences involved both for students and 
teachers. The different genres in which students were asked to write might have also affected the results of this study, because some genres might be more suitable for video feedback than others. Thus, video feedback can be used for action research and exploratory practice by the classroom teachers/researchers to investigate whether the number of certain mistakes and errors decreases over a period of time and in which genres, and if there are any other task-related differences that play a role when students incorporate feedback into their subsequent drafts. According to Warschauer (2002), teachers' assumptions and beliefs about their students' computer literacy determine teachers' use of computers for instructional purposes. Based on our findings, learners' lack of fundamental computer skills should not be considered as a disadvantage for providing video feedback.

In this study, the classroom teachers were reluctant to try this new method of providing feedback in their classes due to their busy schedule, which raises issues regarding the practicality of video feedback. According to Mann (2015), it takes 10-20\% longer to provide video feedback. The whole process of providing video feedback from creating PDFs out of students' essays, learning to use the necessary software, purchasing a licensed one if not using an openlicense software, creating videos, uploading them to YouTube, to finally sharing them with students is labor-intensive and might not be feasible when there is not enough funding, time, or teachers' willingness to engage with the practice. Although the present study only focused on video feedback with regard to students and their improvement in process writing, further studies can shed light on the experiences of teachers with video feedback in a way that highlights advantages and disadvantages. One suggestion to overcome at least one of the above-listed challenges for language teachers and researchers who would like to benefit from video feedback is to use an online management system so that students can post their essays online, and hence their papers will be ready to be processed without the necessity of being scanned and turned into PDFs.

Whether corrective feedback really helps learners in the long run or simply means learners' correcting their written work for the time being is debatable (e.g., Bitchener, 2008; Chandler, 2003; Ferris, 1999; Truscott, 2007). According to Truscott and Hsu (2008), successful error correction by learners in subsequent drafts is not a predictor of learning. The findings of this study suggest that video feedback helps learners incorporate more correction into their subsequent drafts. However, it did not investigate whether learners really learned from their mistakes and errors. Therefore, studies can adopt a longitudinal approach to offer more insights into whether learners learn from video feedback or not.

In conclusion, this study has provided empirical evidence for the advantages of video feedback over written feedback. Although further studies are needed to address its practicality and pedagogical effectiveness, video feedback seems to be an eligible practice in process writing (e.g., Seror, 2012; Stannard, 2007), especially in addressing simple mechanical, complex mechanical, and organizational issues due to its features of conferencing and multimodality.

\section{7 | THE AUTHORS}

Sertaç Özkul studied English language and literature and obtained his EFL teaching certificate in 2005. In 2014, he completed his MA degree at Bilkent University, Ankara, Turkey. He currently teaches EFL to tertiary level students at Trakya University, Edirne, Turkey. His primary focus is on the use of instructional technologies to teach English. 
Deniz Ortaçtepe is an assistant professor in the MA TEFL Program at Bilkent University, Ankara, Turkey. Her research interests are second language socialization, pragmatics, and sociolinguistics. She has published in Teaching and Teacher Education, Journal of Language Identity and Education, System, and Language and Intercultural Communication.

\section{REFERENCES}

Bitchener, J. (2008). Evidence in support of written corrective feedback. Journal of Second Language Writing, 17 (2), 102-118. https://doi.org/10.1016/j.jslw.2007.11.004

Bitchener, J., Young, S., \& Cameron, D. (2005). The effect of different types of corrective feedback on ESL student writing. Journal of Second Language Writing, 14(3), 191-205. https://doi.org/doi.org10.1016/j.jslw.2005.08.001

Boyatzis, R. E. (1998). Transforming qualitative information: Thematic analysis and code development. Thousand Oaks, CA: Sage.

Butler, D. A. (2011). Closing the loop 21st century style: Providing feedback on written assessment via MP3 recordings. Journal of Australasian Law Teachers Association, 4(1\&2), 99-107.

Chandler, J. (2003). The efficacy of various kinds of error feedback for improvement in the accuracy and fluency of L2 student writing. Journal of Second Language Writing, 12(3), 267-296. https://doi.org/10.1016/S1060-3743 (03)00038-9

Crook, A., Mauchline, A., Maw, S., Lawson, C., Drinkwater, R., Lundqvist, K., \& Park, J. (2012). The use of video technology for providing feedback to students: Can it enhance the feedback experience for staff and students? Computers and Education, 58(1), 386-396. https://doi.org/10.1016/j.compedu.2011.08.025

Ferris, D. (1997). The influence of teacher commentary on student revision. TESOL Quarterly, 31, 315-339. https://doi.org/10.2307/3588049

Ferris, D. (1999). The case for grammar correction in L2 writing classes: A response to Truscott (1996). Journal of Second Language Writing, 8(1), 1-11. https://doi.org/10.1016/S1060-3743(99)80110-6

Goldstein, L. M., \& Conrad, S. M. (1990). Student input and negotiation of meaning in ESL writing conferences. TESOL Quarterly, 24, 443-460. https://doi.org/10.2307/3587229

Hyland, F. (1998). The impact of teacher written feedback on individual writers. Journal of Second Language Writing, 7(3), 255-286. https://doi.org/10.1016/s1060-3743(98)90017-0

Hyland, F. (2003). Focusing on form: Student engagement with teacher feedback. System, 31, 217-230. https://doi. org/10.1016/S0346-251X(03)00021-6

Hyland, K., \& Hyland, F. (2006). Feedback on second language students' writing. Language Teaching, 39, 83-101. https://doi.org/10.1017/S0261444806003399

Johnson, K. (2008). An introduction to foreign language learning and teaching (2nd ed.). Harlow, England: Longman.

Keh, C. L. (1990). Feedback in the writing process: A model and methods for implementation. ELT Journal, 44, 294-304. https://doi.org/10.1093/elt/44.4.294

Lee, I. (2003). L2 writing teachers' perspectives, practices and problems regarding error feedback. Assessing Writing, 8, 216-237. https://doi.org/10.1016/j.asw.2003.08.002

Lunt, T., \& Curran, J. (2009). "Are you listening please?" The advantages of electronic audio feedback compared to written feedback. Assessment and Evaluation in Higher Education, 35, 759-769. https://doi.org/10.1080/ 02602930902977772

Mann, S. (2015). Screen capture software to improve the value of feedback on academic assignments in teacher education. In T. Farrell (Ed.), International perspectives on English language teacher education (pp. 160-180). Basingstoke, England: Palgrave Macmillan.

Montgomery, J. L., \& Baker, W. (2007). Teacher-written feedback: Student perceptions, teacher self-assessment, and actual teacher performance. Journal of Second Language Writing, 16(2), 82-99. https://doi.org/10.1016/j.jslw. 2007.04.002

Mukundan, J., \& Nimehchisalem, V. (2011). Effect of peer review and tutor conferencing on English as a second language learners' writing performance. Pertanika Journal of Social Sciences and Humanities, 19(1), $25-38$. 
Seror, J. (2012). Show me! Enhanced feedback through screencasting technology. TESL Canada Journal, 30(1), 104-116. https://doi.org/10.18806/tesl.v30i1.1128

Seror, J. (2013). Screen capture technology: A digital window into students' writing processes. Canadian Journal of Learning and Technology, 39(3), 1-16.

Silva, M. L. (2012). Camtasia in the classroom: Student attitudes and preferences for video commentary or Microsoft Word comments during the revision process. Computers and Composition, 29(1), 1-22. https://doi.org/10.1016/ j.compcom.2011.12.001

Stannard, R. (2006). The spelling mistake: Scene one, take one. Retrieved from http://www.timeshighereducation.co. uk/story.asp?sectioncode $=26 \&$ storycode $=207117$

Stannard, R. (2007). Using screen capture software in student feedback. Heslington, England: The Higher Education Academy, English Subject Centre. Retrieved from http://www.english.heacademy.ac.uk/explore/publications/cases tudies/technology/camtasia.php

Stannard, R. (2008). New directions in feedback. Humanising Language Teaching, 10(6). Retrieved from http:// www.hltmag.co.uk/dec08/mart04.htm

Thompson, R., \& Lee, M. J. (2012). Talking with students through screencasting: Experimentations with video feedback to improve student learning. Journal of Interactive Technology and Pedagogy, 1. Retrieved from https:// jitp.commons.gc.cuny.edu/talking-with-students-through-screencasting-experimentations-with-video-feedback-toimprove-student-learning/

Truscott, J. (2007). The effect of error correction on learners' ability to write accurately. Journal of Second Language Writing, 16(4), 255-272. https://doi.org/10.1016/j.jslw.2007.06.003

Truscott, J., \& Hsu, A. Y. (2008). Error correction, revision, and learning. Journal of Second Language Writing, 17 (4), 292-305. https://doi.org/10.1016/j.jslw.2008.05.003

Warschauer, M. (2002). Networking into academic discourse. Journal of English for Academic Purposes, 1(1), 4558. https://doi.org/10.1016/S1475-1585(02)00005-X

World Bank. (2015). World devlelopment indicators: The information society. Washington, DC: Author. Retrieved from http://wdi.worldbank.org/table/5.12\#

\section{SUPPORTING INFORMATION}

Additional Supporting Information may be found online in the supporting information tab for this article.

How to cite this article: Özkul S, Ortaçtepe D. The use of video feedback in teaching process-approach EFL writing. TESOL Journal. 2017;8:862-877. https://doi.org/10.1002/ tesj.362 


\section{APPENDIX}

\section{COVER SHEET}

CONTROL GROUP

NAME:

\begin{tabular}{|c|c|c|c|}
\hline $\begin{array}{l}\text { Feedback } \\
\text { Category }\end{array}$ & Type of feedback & First Draft & Second Draft \\
\hline \multirow{5}{*}{ Explicit } & Direct answer & & \\
\hline & Capitalization & & \\
\hline & Sing./Pl. & & \\
\hline & Word Order & & \\
\hline & Unnecessary word & & \\
\hline \multirow{3}{*}{$\begin{array}{l}\text { Simple } \\
\text { Mechanical }\end{array}$} & Spelling & & \\
\hline & Punctuation & & \\
\hline & Article & & \\
\hline \multirow{15}{*}{$\begin{array}{l}\text { Complex } \\
\text { Mechanical }\end{array}$} & Missing word & & \\
\hline & Verb tense & & \\
\hline & $\mathrm{S} / \mathrm{V}$ agreement & & \\
\hline & Pronoun agreement & & \\
\hline & $\begin{array}{l}\text { Connect to make } \\
\text { one sentence }\end{array}$ & & \\
\hline & Wrong form & & \\
\hline & Not parallel // & & \\
\hline & $\begin{array}{l}\text { Add a transition } \\
\text { word }\end{array}$ & & \\
\hline & Wrong word & & \\
\hline & Add a conjunction & & \\
\hline & Add a preposition & & \\
\hline & Fragment & & \\
\hline & Reference & & \\
\hline & Run-0n sentence & & \\
\hline & Comma splice & & \\
\hline \multirow{7}{*}{ Organizational } & Too short/too long & & \\
\hline & $\begin{array}{l}\text { Missing/extra } \\
\text { paragraph }\end{array}$ & & \\
\hline & $\begin{array}{l}\text { Supporting ideas } \\
\text { and examples }\end{array}$ & & \\
\hline & $\begin{array}{l}\text { Thesis statement } \\
\text { and introduction }\end{array}$ & & \\
\hline & Conclusion & & \\
\hline & $\begin{array}{l}\text { Irrelevant } \\
\text { information/ } \\
\text { examples / ideas }\end{array}$ & & \\
\hline & Repetition & & \\
\hline
\end{tabular}

WEEK: ...... 